ring could shunt back and forth between two sites on the axle, which was capped at each end by stoppers, and Stoddart and other chemists worked out how to control that process, using changes in acidity, light or temperature.

Since then, Stoddart's team has used similar rotaxanes to make a molecular 'lift', which can raise itself (by less than a nanometre) above a surface, and an artificial 'muscle', in which rotaxanes bend a thin sheet. The researchers have also used millions of rotaxanes to make a high-density memory device - in which the shuttles flick from an 'on' state to an 'off' state.

And in 1999, Feringa was the first to develop a synthetic molecular motor - a single molecule with paddle units connected by a carbon-carbon double bond. The paddles rotated, and kept on spinning, when the bond was broken with light. Feringa showed that the motors could have macroscale effects, such as rotating a glass rod sitting on top of them. Perhaps most famously, Feringa has also created a fourwheel-drive 'nanocar' out of the motors.

\section{WIDER IMPACTS}

The Nobel prizewinners' work - and other chemists' nanomachines - have also had an impact on researchers' understanding of nature, Astumian says. In particular, the artificial systems have helped to demonstrate that all chemically powered molecular

\section{NANOMACHINES}

Mechanisms the size of molecules are governed by the rules of chemistry, rather than Newtonian mechanics. An example is this switch called a rotaxane. A ring-shaped molecule is threaded onto a linear molecule and shifts between two binding sites as the acidity of the surrounding solution is altered.

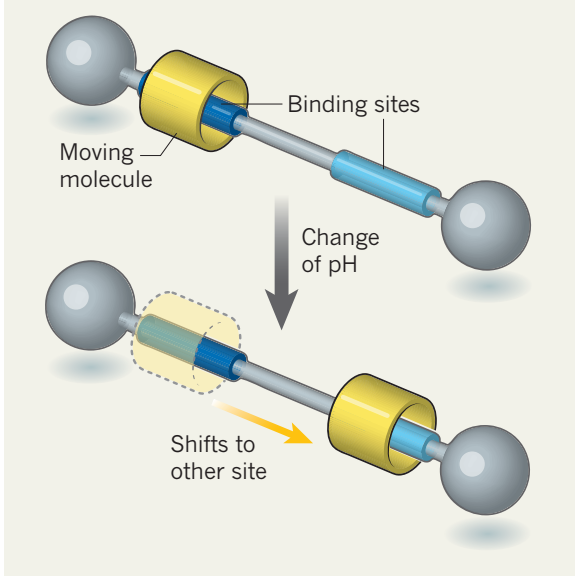

machines, whether synthetic or biological, work on the same principle: they selectively harvest the random jiggles of Brownian motion, rather than push against them.

Asked by reporters at the Nobel press conference whether his machines would find a use, Feringa likened the creators of minuscule machines to the Wright brothers, who made their maiden flight in a powered aircraft more than 100 years ago. "People were saying, why do we need a flying machine? Now we have a Boeing 747 and an Airbus. That's a little bit how I feel. The opportunities are great."

During his own press conference, Stoddart also took political swipes, both at recent UK anti-immigration rhetoric and at US Presidential candidate Donald Trump. He said that his old country, the United Kingdom, was "in a real mess because it thinks it can raise borders to people coming in". And referring to Trump's comment in his first debate with Hillary Clinton that not paying federal taxes would be "smart", Stoddart said that one-third of his Nobel earnings would go to taxes, because, he said, "I am not smart".

\section{CORRECTIONS}

The News story 'Ukraine embraces solar and wind power' (Nature 537, 598; 2016) gave the wrong year for the annexation of the Crimean peninsula. It happened in 2014. And the News story 'Medical award for cell recycling' (Nature 538, 18-19; 2016) gave the wrong affiliation for Hitoshi Nakatogawa - he is at the Tokyo Institute of Technology. 